\title{
An Update on the Biological Activities of Euterpe edulis (Juçara)
}

\author{
Authors \\ Alyne Lizane Cardoso ${ }^{1}$, Sheyla de Liz ${ }^{1}$, Débora Kurrle Rieger ${ }^{1}$, Ana Carolina Aguiar Farah², Francilene Gracieli Kunradi \\ Vieira ${ }^{1}$, Maria Alice Altenburg de Assis ${ }^{1}$, Patricia Faria Di Pietro ${ }^{1}$ \\ Affiliations \\ 1 Department of Nutrition, Graduate Program in Nutrition, \\ Federal University of Santa Catarina, Florianopolis, Brazil \\ 2 Department of Pharmacy, Federal University of Santa \\ Catarina, Florianopolis, Brazil \\ Key words \\ Euterpe edulis, Arecaceae, juçara, açaí, biological effects, \\ antioxidant \\ received June 29,2017 \\ revised January 11,2018 \\ accepted January 21, 2018 \\ Bibliography \\ DOI https://doi.org/10.1055/s-0044-101624 \\ Published online February 21, 2018 | Planta Med 2018; 84: \\ 487-499 @ Georg Thieme Verlag KG Stuttgart · New York I \\ ISSN 0032-0943 \\ Correspondence \\ Prof. Dr. Patricia Faria Di Pietro \\ Programa de Pós-Graduação em Nutrição, Centro de Ciências \\ da Saúde, Universidade Federal de Santa Catarina, Campus \\ Universitário \\ 88040900 Florianópolis/SC, Brazil \\ Phone: + 55 (48) 37218014 , Fax: + 55(48) 37219542 \\ patricia.di.pietro@ufsc.br \\ $\circledast$ \\ Supporting information available online at \\ http://www.thieme-connect.de/products

\section{ABSTRACT} \\ The palm tree Euterpe edulis, known as juçara, produces \\ spherical and purple fruits, similar to those of the Euterpe ole- \\ racea and Euterpe precatoria palm trees, from which the com- \\ mon name açaí originates. Juçara fruit has been gaining prom- \\ inence in the scientific world for its interesting nutritional \\ composition, which is rich in antioxidants, and for its sustain- \\ able production model. Recently, relevant biological activities \\ have been associated with the juçara fruit, and its use in ali- \\ mentation has become an important nutritional, environmen- \\ tal, and economic alternative. The aim of this review is to \\ compile recent scientific data about the phytochemical char- \\ acterization and biological activities of $E$. edulis. A review of \\ the literature was conducted in two electronic databases, \\ Medline and Science Direct. The eligibility criteria were as fol- \\ lows: phytochemicals characterize of the $E$. edulis fruits and \\ evaluate biological effects in vitro or in vivo with pulp, extract, \\ juice, or product of juçara fruits. Investigations were excluded \\ if they used other parts of the plant (seeds), did not assess \\ biological activities, or have tested methodologies for com- \\ pound extraction. From the identified reports, 25 articles \\ were eligible for this study. The promotion of health benefits \\ related to juçara fruits seems to have improved antioxidant \\ activity in vivo, benefits to lipid and glycemic profiles, and \\ modulation of inflammatory status in experimental studies in \\ animals.
}

\section{Introduction}

Studies have reported that fruit consumption promotes protective effects on the body, especially because of the phenolic compounds found in them [1-3]. There is a growing interest in native and exotic fruits from tropical countries, particularly due to their nutritional composition, which includes high levels of anthocyanin (ACNs) [4-5].

Açaí comes from the Euterpe genus palm tree, a member of the Arecaceae family. The most popular species of palm trees which the açaí originates are Euterpe oleracea Martius and Euterpe precatoria Martius [6]. According Yamagichi et al. [6], only these two species are commercially used for their fruits. However, it is possible that sometimes juçara is named açaí to make it commercially relevant, despite belonging to a different species of palm [7].

A native tree of the Atlantic Forest, the palm species Euterpe edulis Martius, popularly known as juçara (or jussara) and açaído-sol, has recently been gaining relevance in the scientific literature. The juçara palm produces a spherical purple fruit, with sensorial characteristics comparable to those of açaí, but with a better nutritional composition [8-12]. However, the excessive extraction of palm heart from the juçara tree has driven it to almost being extinction. For this reason, the sustainable exploitation of this species can make the use of the juçara fruit in alimentation a great nutritional, environmental, and economic alternative $[8,12$, 13]. 


$\begin{array}{ll}\text { ABBREVIATIONS } \\ \text { ACN } & \text { anthocyanin } \\ \text { AIN } & \text { American Institute of Nutrition } \\ \text { ALT } & \text { alanina aminotransferase } \\ \text { ApoE } & \text { apolipoprotein E } \\ \text { AST } & \text { aspartato aminotransferase } \\ \text { CAT } & \text { catalase } \\ \text { DPPH } & \text { radical 2,2-diphenyl-1-picrylhydrazyl } \\ \text { dwb } & \text { dry weight basis } \\ \text { FRAP } & \text { ferric reducing antioxidant potential } \\ \text { fwb } & \text { fresh weight basis } \\ \text { GPX } & \text { glutathione peroxidase } \\ \text { HDL-C } & \text { high-density lipoprotein cholesterol } \\ \text { IFN } & \text { interferon } \\ \text { IL-6 } & \text { interleukin } 6 \\ \text { IL-1 } \beta & \text { interleukin 1 } \beta \\ \text { LDL-C } & \text { low-density lipoprotein cholesterol } \\ \text { NF-KB } & \text { nuclear factor kappa B } \\ \text { ORAC } & \text { oxygen radical absorbance capacity } \\ \text { RDA } & \text { recommended dietary allowance } \\ \text { ROS } & \text { reactive oxygen species } \\ \text { SOD } & \text { superoxide dismutase } \\ \text { sVCAM-1 } & \text { soluble vascular cell adhesion molecule-1 } \\ \text { TC } & \text { total cholesterol } \\ \text { TNFRI } & \text { tumor necrosis factor receptor 1 } \\ \text { TNF- } \alpha & \text { tumor necrosis factor alpha } \\ \text { UCP-1 } & \text { uncoupling protein 1 } \\ & \end{array}$

Studies about the biological effects of the $E$. edulis palm fruit are recent and seem promising. They highlight its antioxidant, anti-inflammatory, and cardioprotective effects [14-18]. In 2016, the chemical constituents and botanical aspects about E. edulis were compiled in Schulz's review [12].

To the best of our knowledge, the present review is the first work that aims to summarize the phytochemical characterization and especially biological activities focusing on the $E$. edulis fruits. $E$. edulis originates from a pulp that some researchers consider very similar to açaí, with interesting nutritional composition. Biological effects related to juçara fruits are emerging in the scientific literature, so it is relevant to compile this data to be aligned with the advancing scientific paths.

The research was conducted on the Medline (via PubMed) and Science Direct (via Scopus) online databases. The articles selected for this study had the following eligibility criteria: without restriction of written language, they had to evaluate some effect of biological relevance in vitro, in vivo, or by clinical trials, with administration of pulp, juice, or extract of juçara fruits; they had to evaluate the phytochemical characterization of juçara fruits and be published in the last five years. The following elements were not considered in this review: studies that evaluated methodologies which optimized extraction of fruit compounds, studies that focused on botanical aspects, and those that evaluated other plant parts (seeds or seed products). A flow chart of the selection of studies is given in the Supporting Information.
The research was conducted between May 2016 and August 2017. Titles and abstracts of the articles were revised, and when the information was not clear, the full text was accessed. Twentyfive articles were selected as eligible for this study, which addressed antioxidant properties, effect on metabolic parameters, anti-inflammatory, and other effects.

\section{Chemical Characterization}

Chemical composition of juçara fruit has been demonstrated in several studies. The juçara fruit must be processed before being consumed. After selection and washing, juçara fruits are macerated and mixed with different amounts of water, where the pulp (epicarp and mesocarp) is separated from the seeds. This process results in a creamy, dark purple liquid with a characteristic flavor, commonly called pulp $[8,10]$. The way of juçara fruit is prepared may result in different chemical compounds [8].

The pulp or drink produced from juçara fruit has important nutritional properties for human nutrition. It can be regarded as an energy source, fiber, ACN, minerals, and unsaturated fatty acids $[8,10]$.

The juçara pulp presents high energy density $(0.8 \mathrm{kcal} / \mathrm{mL})$, mainly by the presence of lipids [11]. Lipids are the main macronutrients of juçara pulp according some authors $[8,11,19]$. Depending on the palms growing region and during the ripening cycle, this content can have a great variation of lipids, around $18.5-44.1 \%$ [8] or from 7.1 to $22.1 \mathrm{~g} / 100 \mathrm{~g}$ on a dry weight basis (dwb) [19], showing a large variation during ripening. Regarding the distribution of fatty acids, the juçara pulp has around $30 \%$ of saturated, $35 \%$ of monounsaturated, and $35 \%$ of polyunsaturated, according to what region in the southern Brazil, state of Santa Catarina, that the fruit grew $[8,19]$. The fatty acids in larger quantities are unsaturated, representing about $50-70 \%$ of the total lipid fraction. On a dwb, the proportions of oleic acid and linoleic acid were between $44 \%$ and $55 \%$ and between $18 \%$ and $25 \%$, respectively [8]. Schulz et al. [19] also found oleic acid as the main fatty acid in dried samples of juçara, representing around 35-42\% of the total fatty acids.

\section{Minerals}

Few studies have identified and quantified minerals in juçara fruit. The most minerals are found in the pulp of these fruits [11].

Da Silva et al. [20] showed a large amount of magnesium in samples of juçara fruit, $974.4 \mathrm{mg} / 100 \mathrm{~g}(\mathrm{dwb})$. However, other studies showed much lower amounts of this mineral, $183 \mathrm{mg} /$ $100 \mathrm{~g}$ (dwb) [19], $98.0 \mathrm{mg} / 100 \mathrm{~g}$ (dwb) [17], and $47.4 \mathrm{mg} / 100 \mathrm{~g}$ (dwb) [11].

Considering the evaluation of copper, the values found by Da Silva et al. [20] and Novello et al. [17] were $9930 \mu \mathrm{g} / 100 \mathrm{~g}$ and $1110 \mu \mathrm{g} / 100 \mathrm{~g}$ on a dwb, respectively. These values were sufficient to reach the RDA values for this mineral (900 $\mu \mathrm{g} /$ day) [21]. Inada et al. [11] demonstrated below $500 \mu \mathrm{g} / 100 \mathrm{~g}$ (dwb).

Although Da Silva et al. [20] showed a large amount of zinc ( $27.1 \mathrm{mg} / 100 \mathrm{~g} \mathrm{dwb}$ ), other studies showed lower levels, followed by Schulz et al. [19] with $2.8 \mathrm{mg} / 100 \mathrm{~g}(\mathrm{dwb})$, Novello et al. [17] with $2.0 \mathrm{mg} / 100$ (dwb), and Inada et al. [11], with $0.9 \mathrm{mg} / 100 \mathrm{~g}$ (dwb). 
Studies demonstrated interesting quantities of manganese by Da Silva et al. [20] and Novello et al. [17], $33.6 \mathrm{mg}$ and $23.9 \mathrm{mg} /$ $100 \mathrm{~g}(\mathrm{dwb})$, respectively, while Schulz et al. [19] and Inada et al. [11] showed lower values of 8.4 and $3.0 \mathrm{mg} / 100 \mathrm{~g}$ (dwb), respectively. Even these differences all values are higher than the adequate intake values for men $(2.3 \mathrm{mg} /$ day) and women $(1.8 \mathrm{mg} /$ day) [21].

Values found for iron are worth mentioning. Da Silva et al. [20] found much higher quantity of this mineral, $65.3 \mathrm{mg} / 100 \mathrm{~g}$ (dwb), compared with the amount presented by other studies, $7.2 \mathrm{mg}$ [19], $5.2 \mathrm{mg}$ [17], and $4.3 \mathrm{mg}$ [11] in $100 \mathrm{~g}$ (dwb). With the exception of the amount showed by Da Silva et al. [20], which exceeds the RDA values (men: $8 \mathrm{mg} / \mathrm{d}$; women: $18 \mathrm{mg} / \mathrm{d}$ ) [21], in $100 \mathrm{~g}$, the others studies have demonstrated to reach almost half of these daily recommendations. Despite the amount of iron found in fruits, their bioaccessible fractions evaluated in vitro seem to be low according to Schulz et al. [22], from 0 to $29.5 \%$ with rates increasing according to the advancement of ripening.

Other nutrients relevant are potassium and calcium. Great amounts of potassium were observed: 998.67 to $1325.88 \mathrm{mg}$ depending of maturation stage (0-69 d [22]) followed by $1291.5 \mathrm{mg}$ [19], $1090.8 \mathrm{mg}$ [20], $892.2 \mathrm{mg}$ [17], and $419.1 \mathrm{mg}$ [11] (all values in $100 \mathrm{~g}$ on a dwb). Regarding calcium, Da Silva et al. [20] found $1040.6 \mathrm{mg} / 100 \mathrm{~g}(\mathrm{dwb})$ and demonstrated that it exceeds the RDA value (men and women: 1000 mg/day) [21], while Schulz et al. [19] showed approximately half the RDA value for this mineral: $596.7 \mathrm{mg} / 100 \mathrm{~g}$ (in the stage 7 of maturation, which corresponds to 69 days after the red berries appeared in bunches). Zero to $69 \mathrm{~d}$ evaluated in seven stages [22]. Novello et al. [17] and Inada et al. [11] showed much lower values, $76.4 \mathrm{mg}$ and $100.0 \mathrm{mg} / 100 \mathrm{~g}(\mathrm{dwb})$, respectively. In addition, calcium presented great bioaccessibility (14.3-65.5\%) compared with other minerals evaluated in different stages of ripening (0-69 d) [22].

For phosphorus, studies show great disparity values, while Da Silva et al. [20] presents $1324.5 \mathrm{mg}$ and Inada et al. [11] and Novello et al. [17] showed 41.2 and $26.7 \mathrm{mg} / 100 \mathrm{~g}$ (dwb), respectively. For sodium, $397.3 \mathrm{mg}$ and $149.3 \mathrm{mg}$ were the highest values found by Silva et al. [20] and Novello et al. [17] per $100 \mathrm{~g}$ (dwb), respectively, while Inada et al. [11] and Schulz et al. [19] showed much lower values, $17.3 \mathrm{mg}$ and $14.2 \mathrm{mg}$ per $100 \mathrm{~g}$ (dwb), respectively.

\section{Vitamins}

According to Rufino et al. [23], the amount of vitamin C presented in juçara fruits, compared to other tropical fruits, is considered modest in quantities of $100 \mathrm{~g}$ of fresh weight basis (fwb). The vitamin C variability may occur due to soil characteristics, weather, agricultural practices, and ripeness stage, as well as due to the harvest, transport, storage, and the depulping process. However, the vitamin $C$ content in juçara pulp is similar to other juices of non-citrus fruits such as blackberry, cranberry, and plum (4$11 \mathrm{mg} / 100 \mathrm{~mL})$ [11].

Rufino et al. [23] reported the amount of $1900 \mu \mathrm{g} / 100 \mathrm{~g}$ (fwb) of the total carotenoids in juçara fruit collected in Santa Catarina, southern Brazil. In contrast, values of total carotenoids founded by Silva et al. [13] and Inada et al. [11] $(737 \mu \mathrm{g}$ and $414 \mu \mathrm{g} / 100 \mathrm{~g}$ fwb, respectively) were lower. Consonant to the classification of carotenoid sources proposed by Britton and Khachik [24] ([per

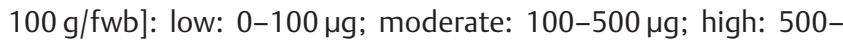
$2000 \mu \mathrm{g}$; and very high: $>2000 \mu \mathrm{g}$ ), juçara pulp may be considered a high or moderate source of carotenoid.

Silva et al. [13] showed a higher value of retinol activity equivalent $(27.8 \mu \mathrm{g} / 100 \mathrm{~g} \mathrm{fwb})$ compared to the study of Inada et al. [11] $(7 \mu \mathrm{g} / 100 \mathrm{~g} \mathrm{dwb})$.

Novello et al. [17] in an experimental study assessed the amount of $\beta$-carotene in lyophilized juçara extract with $23.9 \mu \mathrm{g}$ per kilogram of extract, while Inada et al. [11] reported $86 \mu \mathrm{g} /$ $100 \mathrm{~g}(\mathrm{dwb})$ of $\beta$-carotene in the whole fruit. This amount is higher than the amount of $\beta$-carotene showed in lyophilized extract of açaí (E. oleracea) by Schauss et al. [25], around $3 \mu \mathrm{g} / 100 \mathrm{~g} \mathrm{dwb}$.

\section{Phenolic Compounds}

Juçara palm provides a fruit with high nutritional value, which contains bioactive compounds, such as ACNs, non-ACN flavonoids, and phenolic acids, which are associated with potent biological activities [12]. The $>$ Table 1 summarizes the biological activities tested in E. edulis fruit.

Silva et al. [13] showed a great value of $4087 \mathrm{mg} / 100 \mathrm{~g} \mathrm{dwb}$ to soluble phenolics in juçara pulp with fruits collected in the southeast of Brazil (São Paulo) in its mature stage. Inada et al. [11] found lower content of soluble phenolics (1695 mg/100 g dwb) consisting of $95 \%$ of the total content of phenolic compounds, while insoluble compounds comprise $5 \%$. Juçara pulp sample was produced by Juçai ${ }^{\circledR}$ processing company, 2012 crop, also located in the southeast of Brazil (Rio de Janeiro). Bicudo et al. [10] found much lower values of soluble and insoluble phenolic compounds (244 mg/100 g dwb). The fruits were 2012 crop and were classified into three maturity stages according to their external color.

The profile of phenolic acids in juçara fruit consists in gallic acid, protocatechuic, p-hydroxybenzoic, vanillic, chlorogenic, caffeic, syringic, p-coumaric, sinapinic, and ferulic acids $[9-11,19]$. Inada et al. [11] were the first to identify the phenolic acids mcoumaric, transcinnamic, 4-hydroxyphenylacetic, and 3,4-dihydroxyphenylacetic in juçara pulp.

The amount of phenolic acids varies during the ripening stage in juçara fruits. The majority phenolic acid in all ripening stages of juçara fruit was protocatechuic acid [19]. Other authors reported that the ripening of the fruit and the geographic location may interfere in the phenolic compounds of the fruits of palm juçara [8, 10].

The main constituents of the phenolic compounds in juçara pulp are the ACNs [8-10]. The ACNs found in greater amounts in juçara fruits are cyanidin-3-rutinoside followed by cyanidin-3-glucoside $[8,10,11,13-15,17,26]$. However, De Brito et al. [27] identified a greatest amount of cyanidin-3-glucoside (53\%) and cyanidin-3-rutinoside (46\%).

Others subtypes of ACNs were identified in the samples of juçara by several authors: cyanidin-3-sambunoside [16, 17, 27], pelargonidin-3-glucoside [16, 27], pelargonidin-3-rutinoside [17, $27]$, peonidin-3-rutinoside $[13,16,17]$, peonidin-3-glucoside [10], and delphinidin-3-glucoside [16, 17].

In addition, the study performed by Peron et al. [28] reported that ACNs from juçara degraded more slowly than from grapes (Italy type) after temperature effect $\left(50\right.$ and $\left.90^{\circ} \mathrm{C}\right)$. Although phe- 
- Table 1 Biological activities tested in E. edulis fruit.

\begin{tabular}{|l|l|}
$\begin{array}{l}\text { Refer- } \\
\text { ences }\end{array}$ & $\begin{array}{l}\text { Biological activity } \\
\text { evaluated }\end{array}$ \\
\hline$[22]$ & $\begin{array}{l}\text { Bioaccessibility of bioactive } \\
\text { compounds potential of juçara } \\
\text { fruits exposed to in vitro gastro- } \\
\text { intestinal digestion }\end{array}$ \\
\hline$[19]$ & $\begin{array}{l}\text { Antioxidant activity in } \\
\text { seven different stages of fruit } \\
\text { ripening }\end{array}$ \\
\hline
\end{tabular}

\section{Total phenolics (TP) and Anthocyanins (ACN)}

TP: 79.98 mg (before simulating gastrointestinal digestion)

TP: $19.71 \mathrm{mg}$ (after simulating gastrointestinal digestion) $(100 \mathrm{~g} / \mathrm{dwb})$

ACN: $18.76 \mathrm{mg} / 100 \mathrm{~g} \pm 2.9$ (first stage) to $634.26 \mathrm{mg} / 100 \mathrm{~g} \pm 195.02$ (sixth stage) (fwb)

\begin{tabular}{|l|l|l|}
\hline [9] & $\begin{array}{l}\text { Protective antioxidant effect } \\
\text { on Vero cell culture }\end{array}$ & ACN: ranging $91.52-236.19 \mathrm{mg} / 100 \mathrm{~g}(\mathrm{dwb})$ \\
\hline$[10]$ & Antioxidant properties & $\begin{array}{l}\text { TP: ranging } 81.69-49.09 \mathrm{mg} / \mathrm{g}(\mathrm{dwb}) \\
\text { ACN: ranging } 91.52-236.19 \mathrm{mg} / 100 \mathrm{~g}(\mathrm{dwb})\end{array}$
\end{tabular}

ACN: $2033.7 \pm 28.1 \mathrm{mg} / 450 \mathrm{~mL}$ Cyanidin-3-rutinoside: $480.5 \pm 5.9 \mathrm{mg} / 450 \mathrm{~mL}$ (fwb)

\section{TP: 1783}

Cyanidin-3-glucoside: $425 \pm 8$

Cyanidin-3-rutinoside: $1255 \pm 17$ (mg/100 g on a dwb)

[14] Effect on hepatic oxidative and ACN: 25.83 inflammatory biomarkers in mice

Cyanidin-3-glucoside: 9.52

Cyanidin-3-rutinoside: 16.30 (mg/g on a dwb)
Cyanidin-3-glucoside: $102.9 \pm 4.0 \mathrm{mg} / 450 \mathrm{~mL}$ (fwb)

\section{Results}

Mineral and phenolic compounds content started with 1325.9 and $22.9 \mathrm{mg} / 100 \mathrm{~g}$ respectively, and after in vitro digestion, the maximum values were 556.7 and $14.43 \mathrm{mg} / 100 \mathrm{~g}$ (dwb).

DPPH radicals were higher in the extracts of stages 5 $(3.5 \pm 0.5 \mathrm{mg} / \mathrm{mL})$ and $6(3.0 \pm 0.8 \mathrm{mg} / \mathrm{mL})$. The antioxidant activity by FRAP also showed higher activity in maturation stage 6 . FRAP and DPPH were directly correlated with the ripening process.

Defatted pulp showed the highest total monomeric anthocyanin content versus lipid fraction extracts and presented a higher antioxidant activity, too.

Radical scavenging capacity was DPPH, 655.89-

$745.32 \mu \mathrm{mol} \mathrm{TE} / \mathrm{g}$ and oxygen radical absorbance capacity ORAC, 1088.10-2071.55 $\mu \mathrm{mol}$ TE/g. These authors considered the fruit a new source of antioxidants.

Dose: $450 \mathrm{~mL}$, before and $1 \mathrm{~h}, 2 \mathrm{~h}$, and $4 \mathrm{~h}$ after of single intake by healthy individuals. Interaction on the lipid peroxidation measured by lipid hydroperoxides, with decreasing values over time and treatment effect on GPx.

Phenolic compounds are the main contributors to the antioxidant activity of juçara fruit

The rats that received aerobic moderate-intensity exercise training (EXA and EX groups) showed a significant decrease in SOD activity, but no effect of diet or interaction on SOD was demonstrated. No effect on TC, triacylglycerol and $\mathrm{HDL}-\mathrm{C}$.

The groups treated with $2 \%, 6 \%$, and $10 \%$ of juçara extract and $2 \% \alpha$-tocopherol acetate showed a decreased CAT. The group of animals received diet added $6 \%$ juçara extract showed lower SOD activity than the other groups. Group that received $10 \%$ of juçara added in diet decreased LDL-C and triacylglycerol concentrations.

The groups that received juçara, $2 \%$ and $6 \%$, showed a significant decrease in the enzymatic activities of CAT and SOD when compared to the positive control group. Animals that had $6 \%$ of juçara added in diet lowered the concentrations of LDL-C and TC.

Cyanidin-3-glucoside: 9.52

Cyanidin-3-rutinoside: 16.31 (g/kg/dwb)

The animal groups that received $0.5 \%$ of juçara improved glycemic response.

The offspring, which the maternal diet was added with $0.5 \%$ juçara freeze-dried, decreased triacylglycerol, blood glucose, and weight gain. In addition, the same group increased the anti-inflammatory marker IL-10 and increased the UCP-1 expression in the brown adipose tissue.

The G3 (commercial diet plus 10\% of lyophilized juçara pulp) and G4 (commercial diet plus 10\% of lyophilized and defatted juçara pulp) groups decreased lipid peroxidation. The G4 decreased the enzymatic activity of CAT, GST, and SOD, and still decreased serum levels of TC. The G4 had lower expression of pro-inflammatory cytokines tissue but also was associated with decreased anti-inflammatory biomarkers.

continued 
- Table 1 Continued

\begin{tabular}{|c|c|c|c|}
\hline $\begin{array}{l}\text { Refer- } \\
\text { ences }\end{array}$ & $\begin{array}{l}\text { Biological activity } \\
\text { evaluated }\end{array}$ & Total phenolics (TP) and Anthocyanins (ACN) & Results \\
\hline [39] & $\begin{array}{l}\text { Antioxidant and toxic effects } \\
\text { on cardiac and renal tissues } \\
\text { of Wistar rats }\end{array}$ & Data not shown & $\begin{array}{l}\text { The main results were a significant increase in CAT activity } \\
\text { in tissues of animals fed with cafeteria diet plus } 5 \% \\
\text { of } E \text {. edulis lyophilized extract, plus } 10 \% \text { of } E \text {. edulis lyophi- } \\
\text { lized extract and } 10 \% \text { E. edulis defatted lyophilized extract. } \\
\text { No effect was reported on lipid peroxidation in cardiac and } \\
\text { renal tissues after juçara intervention. }\end{array}$ \\
\hline [32] & $\begin{array}{l}\text { Effects of juçara bioproducts } \\
\text { (lyophilized pulp, defatted } \\
\text { lyophilized pulp, and oil) on } \\
\text { nonalcoholic fatty liver } \\
\text { disease induced by a high-fat } \\
\text { diet in rats }\end{array}$ & $\begin{array}{l}\text { TP }(\mathrm{mg} \text { GAE/g) (dwb): } \\
4.10 \pm 0.13 \text { (lyophilized pulp } \\
4.95 \pm 0.07 \text { defatted lyophilized pulp } \\
\text { ACNs (mg GAE/g) (dwb): } \\
2130 \pm 114 \text { (lyophilized pulp } \\
3,121 \pm 139 \text { defatted lyophilized pulp }\end{array}$ & $\begin{array}{l}\text { The groups that received pulp (defatted or not) attenuated } \\
\text { the steatosis and lipid peroxidation in tissues, while the oil } \\
\text { did not show the same effect. The most promising product } \\
\text { appeared to be lyophilized pulp defatted, possibly due low } \\
\text { lipid content and high ACNs and phenols }\end{array}$ \\
\hline [60] & $\begin{array}{l}\text { Inflammatory state in offspring } \\
\text { for which maternal diet con- } \\
\text { tained juçara pulp }\end{array}$ & $\begin{array}{l}\text { ACN: } 262.4 \pm 8.6 \\
\text { Cyanidin-3-glucoside: } 71.4 \pm 2.1 \\
\text { Cyanidin-3-rutinoside: } 191.0 \pm 6.5 \\
\text { TP: } 415.1 \pm 22.3(\mathrm{mg} / 100 \mathrm{~g} \text { on a fwb) }\end{array}$ & $\begin{array}{l}\text { Adding } 0.5 \% \text { of juçara in maternal diet restored the fecal } \\
\text { content of Bifidobacterium spp. and increase colonic ZO- } 1 \\
\text { mRNA expression. Still, the same group decreased pro- } \\
\text { inflammatory markers and increased anti-inflammatory } \\
\text { mediators. }\end{array}$ \\
\hline [52] & $\begin{array}{l}\text { The effect of juçara supple- } \\
\text { mentation in the maternal } \\
\text { diet on the inflammatory state } \\
\text { of the colon in offspring ex- } \\
\text { posed to perinatal and on lipid } \\
\text { profile and glucose }\end{array}$ & Data not shown & $\begin{array}{l}\text { The groups of (pregnant or lactating) rats that receiving } \\
\text { diet with } 0.5 \% \text { juçara (C) and TJ) decrease pro-inflamma- } \\
\text { tory. In contrast, the cytokine anti-inflammatory was } \\
\text { higher in the } C \text { J group than in the T group. Still the groups } \\
\text { that received juçara freeze-dried powder (control diet with } \\
0.5 \% \text { of juçara added) decreased the TC and triglycerides. } \\
\text { The groups that received juçara (C) and TJ) decreased se- } \\
\text { rum levels of glucose. }\end{array}$ \\
\hline [26] & $\begin{array}{l}\text { In vitro fermentation by } \\
\text { human colonic microbiota }\end{array}$ & $\begin{array}{l}\text { TP: } 3474 \pm 98.0 \\
\text { Cyanidin-3-rutinoside: } 966 \pm 54.9 \\
\text { Cyanidin-3-glucoside: } 322 \pm 43.7 \text { (mg/100 g on a } \\
\text { dwb) }\end{array}$ & $\begin{array}{l}\text { The intestinal microbiota in vitro was modulated by juçara } \\
\text { pulp, which was capable of altering the population of the } \\
\text { microbiota and short-chain fatty acids production. }\end{array}$ \\
\hline [65] & $\begin{array}{l}\text { Added juçara pulp and com- } \\
\text { mercial probiotic (Lactobacillus } \\
\text { acidophilus) in yogurt to evalu- } \\
\text { ate the survival probiotic in } \\
\text { storage and after gastric and } \\
\text { enteric digestion in vitro }\end{array}$ & Data not shown & $\begin{array}{l}\text { Juçara pulp seems a good strategic for the production of } \\
\text { yogurts increasing the resistance of probiotics for until } \\
14 \mathrm{~d} \text { of storage even after the stimulation of gastrointesti- } \\
\text { nal conditions. It is suggested with this study that poly- } \\
\text { phenols in particular ACNs may have improved the pro- } \\
\text { biotic viability. }\end{array}$ \\
\hline
\end{tabular}

nolic compounds still found after temperature effect, the $90{ }^{\circ} \mathrm{C}$ decreased the antioxidant activity of the extracts. However, in spite of these results, it is emphasized that the ingestion of juçara is preferably in its fresh form, after processing the fruits with addition of water.

A recent research investigated the major ACNs and non-ACN phenolic compounds in juçara extracts using ultra performance liquid chromatography-mass spectrometry. This study found high amounts of ACN, about $26 \mathrm{mg} / \mathrm{g}$ dwb from a total of $31 \mathrm{mg} / \mathrm{g} \mathrm{dwb}$ of phenolic compounds. Cyanidin-3-O-rutinoside was the most abundant ACN (73\% of the total phenolic compounds content). Other phenolic compounds found in the extract were cyanidin-3O-glucoside, pelargonidin-3-O-glucoside, quercetin, rutin, myricetin, kaempferol, kaempferol-3-O-rutinoside, luteolin, apigenin, catechin, ellagic acid, and 4,5-dicaffeoylquinic acid. The authors considered juçara a promising source of polyphenolics, mainly ACNs [29].

The chemical structures of ACNs known in juçara fruit are presented in $>$ Fig. 1.
It is noteworthy that the nutritional composition and content of the bioactive compounds of juçara may suffer variations, since they are influenced by several factors: the chosen samples, place of harvest of the fruits, and differences in growing conditions of the palm trees, such as altitude, light, and fruit maturation stage $[8,9,13,19]$.

\section{Antioxidant Activity}

The juçara fruit is considered a fruit rich in phenolic compounds. For this reason, the antioxidant effect is the most described for juçara fruits ( $E$. edulis). The free radical-scavenging abilities are reported for the several studies $[10,15,19]$.

The antioxidant capacity of juçara fruit extracts have been reported by several studies, the deactivation of DPPH parameter [8, $10,16,19,23,30]$ and $\operatorname{FRAP}[9,11,16,19,23,30]$ being the most studied. The ORAC has already been used $[10,11]$. 

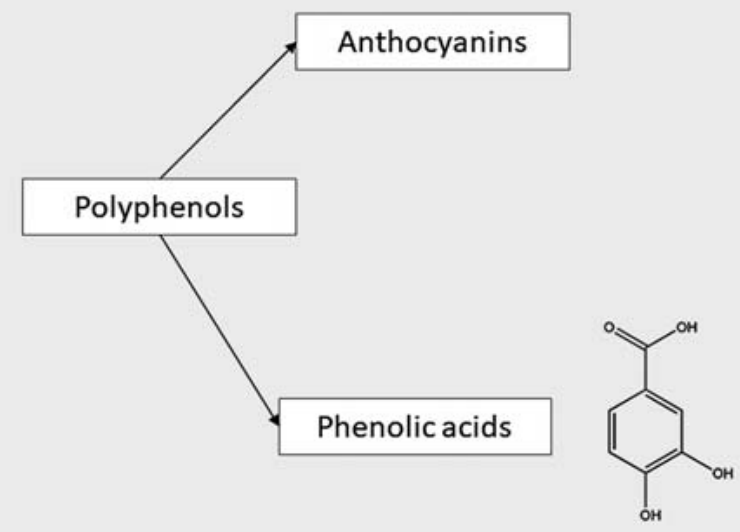

Protocatechuic acid

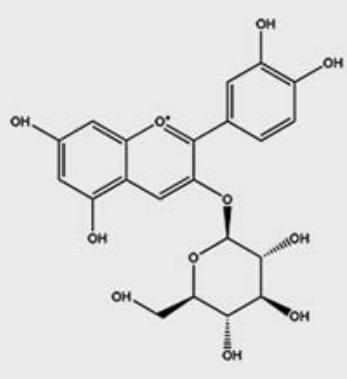

Cyanidin 3-ghucosido

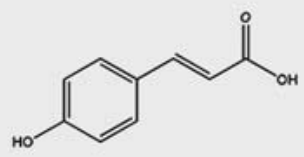

p-coumaric acid
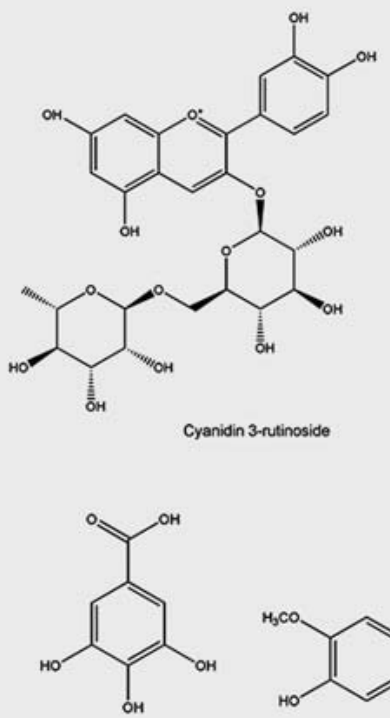

Gallic acid

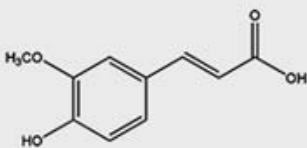

Ferulic acid

- Fig. 1 The structures of the most commonly found compounds in Euterpe edulis.

The antioxidant capacity assessed by FRAP values are different: $1158.0 \mu \mathrm{mol}$ of Trolox equivalent/100 g (dwb) [9] and $2155 \mu \mathrm{mol}$ Trolox equivalent/100 g (dwb) [15].

Values for parameter DPPH presented great variation, as demonstrated by Bicudo, Ribani and Beta [10] (745.3 $\mu \mathrm{mol}$ of Trolox equivalent/g on a dwb), when compared to those presented by our research group in the Cardoso et al. [15] study $(2802 \mu \mathrm{mol}$ of Trolox equivalent/g on a dwb). The DPPH values in juçara samples are higher than the values found for açaí fruit (E. oleracea and E. precatoria, 133.4 and $320.3 \mu \mathrm{mol}$ of Trolox equivalent $/ \mathrm{g} \mathrm{dwb}$, respectively) [31].

The ORAC values in juçara pulp range between 1088.10 and $2071.55 \mu \mathrm{mol}$ Trolox equivalent/g dwb in study performed by Bicudo et al. 2014 [10], while the ORAC values reported by Inada et al. [11] were intermediary (1544 $\mu \mathrm{mol}$ Trolox equivalent/g dwb) in comparison than those cited [10]. Despite the fact that both studies considered freeze-dried samples, the Bicudo et al. [10] samples from southern Brazil were processed by the researchers prior to the analysis, whereas the fruits used by Inada et al. [11] from southeast Brazil were processed by a specialized company. The antioxidant capacity values of juçara fruit between studies suggests high antioxidant capacity of these fruits. However, differences in relation to the results between investigations may be attributed to growth period, growing season, location geographical, cultivar variation, sample extraction methods used, differences in the units reported, and spectrophotometric standards employed, which make a direct comparison difficult.

Despite the potential antioxidant effect already well demonstrated in vitro, few clinical trials evaluated oxidative stress biomarkers in vivo. The bioactive compounds of the berries exert important relation with the oxidative stress acting as scavengers for free radicals. Oxidative stress happens due to the imbalance be- tween the cellular production of reactive species and the antioxidant capacity to defeat these injuries [32]. Excessive reactive oxygen species (ROS) productions are related to cell damage, necrosis, and cell apoptosis due to oxidation of protein, lipids, and DNA [33].

A recent study evaluated the bioproducts of $E$. edulis (lyophilized pulp, defatted lyophilized pulp, and oil) effects on nonalcoholic fatty liver disease induced by a high-fat diet for $4 \mathrm{wk}$. The rats were divided into standard diet, high-fat diet alone, or combined with oil, lyophilized pulp, or defatted lyophilized pulp. The groups that received pulp (defatted or not) attenuated the steatosis and lipid peroxidation in tissues, while the oil did not show the same effect. The most promising product appeared to be lyophilized pulp defatted, possibly due low lipid content and high ACNs and phenols [34]. Lipids are susceptible targets of oxidation because of their molecular structure, and their peroxidation is proposed as markers of lipid damage [35]. Further, anthocyanins are potent antioxidants which act on the attenuation of lipid peroxidation through donation of electrons or hydrogen atoms to reactive species. [36].

An investigation evaluated the combination of freeze-dried juçara pulp added to diet or in combination with moderate-intensity aerobic exercise training on hepatic oxidative stress and inflammatory markers in ApoE - /- mice [14]. Animals that received exercise showed decreased SOD activity independent of juçara intervention diet, there being an effect of exercise on SOD activity. The explanation for the decrease in SOD activity is that the liver reduced ROS generation due the exercise. It is suggested that stress oxidative reduction plays a role with decrease the requirement of protective response because of exercise training [14].

However, other experimental studies observed effect on antioxidant enzymes after intervention with juçara extract. A study 
assessed the antioxidant enzymes in the livers of ApoE - /- mice with freeze-dried juçara extract intervention after selecting the best method to ACN extraction [17]. The extraction method with ethanol and citric acid resulted in the highest ACN concentration. The animals were divided into five groups: positive control - G1 (ApoE knockout, received AIN-93 M), negative control - G2 (C57BL/6, received AIN-93 M), G3, and G4 (ApoE knockout, received AIN-93 M plus 2\% and $6 \%$ freeze-dried juçara extract, respectively), and G5 (ApoE knockout, received AIN-93 M plus $50 \mathrm{mg} / \mathrm{kg} / \mathrm{d}$ of simvastatin). A significant decrease in enzymatic activities of CAT and SOD was observed in G3 and G4 when compared to the treatment pattern (positive control). Authors reported that juçara extract possibly supplied the antioxidant activity exerted by these enzymes through the action of ACNs and their metabolites.

Another study evaluated the antioxidant potential of juçara fruit intervention in dyslipidemic mice (ApoE $-/-$ ). The groups treated with $2 \%, 6 \%$, and $10 \%$ of juçara extract added to diet and a $2 \% \alpha$-tocopherol acetate diet showed decreased CAT activity compared to the control mice (C57BL/6) with a standard diet. In addition, the group of animals that received a diet with $6 \%$ juçara extract showed smaller SOD activity as the other groups [16].

ApoE - /- mice have disabilities in a protein receptor and for this reason have elevated cholesterol levels and high susceptibility to develop atherosclerosis and hepatic steatosis [37]. These animals have been used to explore risk factors for lipid metabolism disorders and therapeutic potential of natural compounds on liver diseases. These conditions are related to the exacerbated production of reactive species $[16,38,39]$, and therefore, dietary sources rich in phenolic compounds with antioxidant potential are of great interest, as in the case of the juçara fruit.

The recent study by Freitas et al. [40] investigated the effect of the juçara intervention during $50 \mathrm{~d}$ in four groups of Wistar rats: commercial diet (control), G2 (commercial diet plus E. edulis [4\%]), G3 (commercial diet plus lyophilized pulp [10\%]), and G4 (commercial diet plus lyophilized and defatted pulp [10\%]). The results showed that the G3 and G4 groups decreased lipid peroxidation. In addition, the group that received defatted pulp decreased the enzymatic activity of CAT, glutathione S-transferases and SOD when compared to the other groups. The higher content of ACNs in G4 may have contributed to modulation of the redox potential.

Freitas et al. [41] investigated the antioxidant and toxic effect after juçara intervention on renal and cardiac tissues in Wistar rats fed with cafeteria diet. The main results were a significant increase in CAT activity in tissues of animals fed with cafeteria diet plus $5 \%$ of $E$. edulis lyophilized extract, plus $10 \%$ of $E$. edulis lyophilized extract and $10 \%$ E. edulis defatted lyophilized extract. No effect was reported on lipid peroxidation to cardiac and renal tissues after juçara intervention. The study suggests a decrease of oxidative stress levels due to the increase of enzymatic activity in cardiac tissues of animals fed with $E$. edulis. The authors hypothesized that extracts of $E$. edulis would prevent the inhibition of the expression of these enzymes, thus promoting the increase of the activity of some antioxidant enzymes.

To the best of our knowledge, the only clinical trial with humans was carried out by our research group. In a clinical trial with juçara juice ingestion, healthy individuals had biomarkers of oxidative stress assessed before and after $1 \mathrm{~h}, 2 \mathrm{~h}$, and $4 \mathrm{~h}$ of a single intake of $450 \mathrm{~mL}$. The fruits were processed with the addition of water, and there were $33.4 \mathrm{~g}$ total solids of juçara in the ingested sample. Repeated measures of analysis variance revealed a significant interaction (between time and treatment) with decreased lipid peroxidation over time. Treatment had a significant effect on GPx, with a maximum activity of $2 \mathrm{~h}$ after acute consumption. This is the first and only evidence that has been found regarding juçara fruit ingestion by humans and showed a positive effect of juçara juice on the antioxidant status and oxidative damage of healthy subjects [15].

The results of experimental studies that evaluated the effect of intervention with juçara on antioxidant enzymes still remain controversial. Some studies have shown a decrease in the activity of antioxidant enzymes such as SOD and CAT $[16,17,40]$, while other studies have reported an increase in the enzymatic activity of CAT tissue in an animal model [41] and GPx in a hemolyzed human clinical trial [15].

Exogenous antioxidants from diet can improve endogenous antioxidant activity through consolidation of defense mechanisms against excessive reactive species neutralizing free radicals or decreasing their level of activity $[5,42]$.

According to Lei et al. [43], the antioxidant enzymes promote the passage of electrons and thus the neutralization of reactive species. Thus, the reduction of the generation of reactive species or their attenuation can be correlated with the decrease of the expression of the antioxidant enzymes. The decrease in the generation of reactive species can occur through the action of bioactive compounds present in the extracts, such as ACNs and their metabolites [44], which can reach the tissues and affect endogenous antioxidant potential.

However, it is proposed that by indirect pathways ACNs could stimulate endogenous antioxidant defense by some mechanisms such as activating genes that encode enzymes [45], repairing and stimulating the activity of the antioxidant enzymes SOD and GPx, and so improving the glutathione [46]. Considering clinical trials and effect of ACN-rich fruits, in general the modulation of endogenous antioxidant enzymes remains uncertain, since some papers report an increase following intervention while others presented no significant findings [35]. Still, enzymatic antioxidant activity is influenced by several factors, such as the animal model and the type of extract used in experimental trials [16].

Considering the effect of the juçara extract on lipid peroxidation, some studies have demonstrated the attenuation of this biomarker of oxidative damage $[15,34,40]$.

Lipid peroxidation is a process associated with a significant production of reactive species inside cells. These processes could cause damage of membranes, proteins, and DNA. For this reason, the decrease of free radicals production can consequently generate less injury to the cellular structures [39].

The phenolic compounds are usually related to the bioactive properties and modulation of oxidative stress biomarkers. The decrease of lipid peroxides in serum possibly happened due the absorption of juçara polyphenols, which probably acted to eliminate free radicals or scavenging peroxyls radicals. For this reason, it is necessary to further research the bioavailability of the main bioac- 
- Table 2 Experimental studies investigating the effect on lipid profile after $E$. edulis supplementation.

\begin{tabular}{|c|c|c|c|c|c|c|c|}
\hline Authors & Animal Model & Time & $\begin{array}{l}\text { Concentration } \\
\text { added in diet }\end{array}$ & HDL-C & LDL-C & Cholesterol Total & Triacylglicero \\
\hline$[14]$ & ApoE knockout & 12 wk & $2 \%$ & No effect & No evaluated & No effect & No effect \\
\hline \multirow[t]{3}{*}{ [16] } & \multirow[t]{3}{*}{ ApoE knockout } & \multirow[t]{3}{*}{$75 d$} & $2 \%$ & No effect & No effect & No effect & Decreased \\
\hline & & & $6 \%$ & Decreased & No effect & No effect & Decreased \\
\hline & & & $10 \%$ & Decreased & Decreased & No effect & Decreased \\
\hline \multirow[t]{2}{*}[17]{} & \multirow[t]{2}{*}{ ApoE knockout } & \multirow[t]{2}{*}{$75 d$} & $2 \%$ & No effect & Decreased & No effect & No effect \\
\hline & & & $6 \%$ & No effect & Decreased & Decreased & No effect \\
\hline [18] & $\begin{array}{l}\text { Without specific } \\
\text { model }\end{array}$ & $10 \mathrm{wk}$ & $2 \%$ & No evaluated & No evaluated & Increased & No effect \\
\hline$[40]$ & $\begin{array}{l}\text { Wistar } \\
\text { (Rattus norvergicus) }\end{array}$ & 4 wk & $10 \%$ & No effect & No effect & Decreased & No effect \\
\hline [54] & Wistar & $3 w k$ & $0.5 \%$ & No effect & No evaluated & Decreased & Decreased \\
\hline [55] & Wistar & $3 w k$ & $0.5 \%$ & No effect & No evaluated & Decreased & Decreased \\
\hline
\end{tabular}

tive compounds present in juçara fruits and their metabolites generated during digestion and absorption in humans or in vivo experimental models, making possible the confirmation of the suggested human healthy-promoting effects.

\section{Metabolic Parameters}

Several studies have related the effect of ACN-rich fruits on metabolic parameters, especially on biomarkers associated with cardiovascular protection. The cardioprotective effects of such diets are often attributed to their polyphenol content $[47,48]$.

Cardiovascular diseases (CVD) are the main public health problem in modern life [47]. Lipoproteins biomarkers may serve as predictor parameters to analyze risk factors or protection for CVD. High levels of LDL-C and very low-density lipoprotein are associated with a higher risk of developing CVD, while HDL-C values are considered as a protection factor $[49,50]$.

Berries can be related in the prevention of atherosclerosis by inhibiting lipid peroxidation and improving the antioxidant status $[47,48]$. Other effects of berries are associated with reducing the cholesterol levels and so decreasing the possibility of endothelial damage and cholesterol deposition in the cells [40]. In this context, benefits on metabolic parameters, especially lipid profile, are associated with ACNs. The action of ACNs is related to a decrease in LDL-C, inhibition of lipid oxidation, and increased fecal excretion of sterol acids [51,52].

The nutritional composition of juçara fruit is interesting, and fruits rich in ACNs are also an excellent source of unsaturated fatty acids $[8,19]$. These unsaturated fatty acids are associated with health benefits by decreasing triacylglycerols and hepatic lipogenesis [53].

In recent years, the evaluation of metabolic parameters in animal experimental studies from the administration of juçara has called the attention of researchers. Some studies in vivo use ApoE-deficient mice due to the accelerated atherosclerosis process. In the analyzed studies, only three investigations evaluated the effect of juçara on ApoE mice $[14,16,17]$. > Table 2 present results of experimental studies that investigated $E$. edulis supplementation effect on lipid profile.

In one study, a group of ApoE knockout mice that received 10\% juçara extract supplementation had a significant decrease in weight compared to the groups supplemented with $2 \%$ and $6 \%$ of juçara extract and with $2 \% \alpha$-tocopherol acetate [16]. The group that received $10 \%$ of juçara extract presented a decrease in non-HDL-C concentrations compared to the groups that received $2 \%$ juçara extract and $2 \% \alpha$-tocopherol acetate supplementation. The most important effect was a decrease in the triacylglycerol concentration in groups of animals that received juçara extract $(2 \%, 6 \%$, and $10 \%)$ supplementation, which is a fact that could be involved in the attenuation of hepatic steatosis [16].

An experimental model study with pregnant rats reported juçara's effect on the lipid profile, glucose, and inflammatory markers during pregnancy and lactation [54]. The groups that received juçara freeze-dried powder for $21 \mathrm{~d}$ (control diet with $0.5 \%$ of juçara added $[\mathrm{CJ}]$ and diet enriched with hydrogenated vegetable fat with $0.5 \%$ of juçara [T]]) decreased the TC and triglycerides concentrations compared to the group that only received a hydrogenated vegetable fat diet. A recent study which used a very similar protocol to that of the study by Morais et al. [54] reported decreases in weight gain and triglycerides in offspring whose mothers were fed diets with $0.5 \%$ juçara freeze-dried powder during pregnancy and lactation.

In the other investigation (more details of which can be found in the Antioxidant Activity section), the groups that received the standard diet AIN-93 M supplemented with 2\% and 6\% of freezedried juçara, or a standardized diet AIN-93 M plus $50 \mathrm{mg} / \mathrm{kg} / \mathrm{d}$ of simvastatin, showed a significant reduction in glucose, LDL-C, and ratios of TC/HDL-C and LDL-C/HDL-C compared to the treatment pattern (positive control). The animals that received juçara extract ( $2 \%$ and $6 \%$ ) showed lower values of TC, showing good results on the reduction of cardiovascular risk [17].

A study presented the juçara supplementation effect of $10 \mathrm{wk}$ on metabolic parameters in rats subjected to high fat and high calorie diets. The main result was that the groups that received 
$0.5 \%$ of juçara improved their glycemic response. The animals that received hypercaloric and hyperlipidemic diets in conjunction with $0.5 \%$ and $2 \%$ of juçara did not present changes in body composition. Unexpectedly, animals that received normocaloric diet with addition of $2 \%$ juçara gained body mass. Adiponectin values of the group with $0.5 \%$ of juçara supplementation decreased compared to the control group [18].

A recent study [40] reported that groups of Wistar rats that receive lyophilized and defatted pulp of juçara (10\%) decreased serum levels of TC, while other parameters such as glucose, triglycerides, HDL-C, AST, and ALT did not show any significant differences between the groups. The results presented by Castro et al. [14] are in agreement with other studies $[18,40]$, reporting no effect of the intervention on lipid profile in an experimental animal trial.

The different animal models and concentrations of juçara in experimental studies make difficult to compare the investigations. Some investigations reported weight loss $[16,55]$, decreased triglycerides $[16,54,55]$, reduction of $\operatorname{LDL}-\mathrm{C}[16,17]$, and decreased of TC $[17,40,54]$, while other animal investigations have reported no effect on the lipid profile $[14,18,40]$. Despite the cardioprotective effect of berries being widely studied due to their content of bioactive compounds and ACNs, the effects of juçara intervention on lipid profile still seem inconclusive. For this reason, further studies are encouraged.

Considering juçara's effect on the blood glucose, a study carried out by Oyama et al. [18] had as a main result the improvement of glycemic response in mice fed with normocaloric, hypercaloric, or hyperlipidemic diet added with $0.5 \%$ of juçara freezedried powder concentration. In the same way, the study by Argentato et al. [55] was also effective in decreasing blood glucose after the addition of $0.5 \%$ juçara freeze-dried powder concentration in the offspring during their maternal diet. Other studies reported a significant decrease in blood glucose after $2 \%$ and $6 \%$ of juçara freeze-dried extract in the diet of ApoE knockout mice compared to the control group [17].

There is evidence that phenolic compounds may promote glucose homeostasis through the stimulation of type 4 glucose transporters. In addition, ACNs can activate protein kinase by adenosine monophosphate, which acts on the uptake of glucose by tissues promoting lipolysis and reduction of cholesterol synthesis [56].

Evidence presented by experimental studies in animals seems promising; however, there is a concern that there is not a longterm clinical trial in humans to better clarify the effects of juçara pulp or juice intake on metabolic parameters affecting the prevention or treatment of chronic diseases. Animal studies are important for assessing potential biological activities but should be interpreted with caution because of these models' limitations.

In addition, randomized controlled trials are the most reliable investigations to infer cause and effect relationships. In order to establish interactions between phenolic compounds and clinical outcomes, controlled interventions are necessary [48].

It is noteworthy to mention that, despite the possible health benefits of juçara fruit for metabolic rates/biomarkers, standardizing strategies for obtaining more exact conclusions still deems necessary to more accurately verify the influence of juçara inter- vention as preventative or complementary treatment for chronic illnesses. These are concentration levels of juçara extract used in diets, whether it is used as juice, pulp, or freeze-dried powder; the time of consumption of participants, and laboratory biomarkers.

It is necessary to consider the differences between the bioavailability of phenolic compounds between animals and humans [48]. In this way, the most effective method of assessing the actual effect of polyphenol-rich interventions in humans, especially on cardioprotection, would be through controlled and randomized controlled trials appropriately powered [48].

More attempts and efforts should be directed to elucidate the mechanisms related to the effects of juçara fruits through in vivo models, considering metabolites of phenolic compounds at biological concentrations.

\section{Anti-Inflammatory Effect}

Inflammation is a process of the immune system characterized as a response to some injury. Cytokines are immune-modulatory molecules that are used as markers to assist the quantification of the inflammatory response [57].

$N F-\kappa B$ is a transcription factor that when activated stimulates the expression of genes responsible for the production of cytokines. Pro-inflammatory biomarkers include acute phase proteins, cytokines (TNF- $\alpha$, IL-6, IL-1 $\beta$, monocyte chemoattractant protein 1 ), and adhesion molecules (E-selectin, P-selectin, soluble vascular cell adhesion molecule-1, soluble intercellular adhesion molecule1). Anti-inflammatory markers can be evaluated by cytokines such as IL-10 and adiponectin [57]. In addition, gene expression of transcription factors and receptors in immune cells should be stimulated or inhibited being also considered biomarkers of the inflammatory state [57].

The inflammatory response may influence reactive oxygen species production and thus redox status. This cycle favors the environment of oxidative stress and inflammatory status, causing health damage and promoting the development of chronic diseases [57].

In this context, the phenolic compounds could confer protection against chronic diseases related to inflammation [57]. Polyphenols may act to activate or inhibit various signaling pathways by modulating proteins, resulting in the activation of transcription factors (for example, NF erythroid 2-related factor 2, NF-kB, changing receptor activation as well as its ligands as proliferatoractivated receptor $\gamma$ [58].

The subclass of polyphenols, with significant quantities in the juçara fruit, are ACNs. It is suggested that important biological activities of berries are related to ACNs, such as anti-inflammatory effect $[57,59]$. The ACN's action on inflammatory state can occur through the control of cells migration and proliferation, as well as by inhibiting the production of inflammatory mediators $[57,59$, 60].

Finding dietary strategies that perform on the inflammatory state have important implications for reducing the risk of chronic diseases and may help to update guidelines with target of promoting health [57].

Some experimental animal studies have evaluated the juçara supplementation effect on inflammatory markers. In the study re- 
ported by Freitas et al. [40] (more details of it can be found in the Antioxidant Activity section), the G4 (10\% of juçara lyophilized and defatted extract added in the diet of Wistar rats for $50 \mathrm{~d}$ ) had lower expression of pro-inflammatory cytokines tissue (IL17 , IFN- $y$, and TNF- $\alpha$ ) compared to the other groups (oil and only lyophilized pulp). However, the G4 was also associated with decreased anti-inflammatory biomarkers (IL-4 and IL-10) compared to the other treatments. A decrease in pro-inflammatory cytokines production can generate a reduction in anti-inflammatory mediators contributing to maintain tissue homeostasis [61]. The juçara supplementation was considered a promising alternative to modulate the inflammatory response.

A study [55] supplemented juçara (0.5\%) in control diet and diet enriched with hydrogenated vegetable oil (with high content of trans fatty acids) on maternal diet during pregnancy and lactation in Wistar rats. The results showed that diets with a high content of trans fatty acids increased inflammatory markers (TNF- $\alpha$ and TNFRI), which was expected, whereas the groups receiving juçara increased the anti-inflammatory marker IL-10 concentration in the brown adipose tissue.

The study carried out by Morais et al. [54] (more details in the Metabolic Parameters section) reported that the groups of (pregnant or lactating) rats that received diet with $0.5 \%$ juçara $(\mathrm{C}$ ) and TJ) decreased pro-inflammatory cytokines IL- 6 and TNF- $\alpha$ and gene expression of IL-6R, TNF- $\alpha$, and toll-like receptor-4. In contrast, the cytokine anti-inflammatory IL-10 and IL-10/TNF- $\alpha$ ratio was higher in the $\mathrm{C}$ group than in the $\mathrm{T}$ group. The authors believe that the anti-inflammatory effect of juçara may be associated to the polyphenols content, particularly ACNs and polyunsaturated fatty acids.

Morais et al. [62] observed an experimental animal study that supplementation with $0.5 \%$ juçara in diet with hydrogenated vegetable fats (diet rich in trans fatty acids) decreased NF- $\kappa$ B pathway activation and TNF- $\alpha$ receptor I in the liver of rats. Possibly, these effects contributed to the decrease of the pro-inflammatory markers IL-6 and TNF- $\alpha$ expression in the liver and the retroperitoneal white adipose tissue. In addition, the groups that received intervention with $0.5 \%$ of juçara increased anti-inflammatory markers such as IL-10 and IL-10/TNF- $\alpha$ ratio in the offspring's liver compared to the group that received just diet enriched with hydrogenated vegetable fats. The phenolic content in maternal diet had a protective effect against the inflammation status.

An experimental study reported that an intake of $2 \%$ of juçara freeze-dried powder in hypercaloric and hyperlipidic diet of mice promotes a reduction of IL-10 in epididymal adipose tissue and IL6 in mesenteric adipose tissue, this way decreasing the inflammation. However, the $0.5 \%$ juçara concentration was not able to change this process [18].

A study carried out by Castro et al. [14] reported a $42 \%$ decreased in monocyte chemotactic protein-mRNA 1 expression (marker related with the atherogenic process) was found in the liver of ApoE knockout mice exposed to the exercise training only. The juçara supplementation showed no effect on this marker.

Juçara seems to affect inflammatory status in favorable ways in experimental animal studies. Most of the studies analyzed showed a decrease in the pro-inflammatory markers after supplementation with juçara, particularly the markers TNF- $\alpha[40,54,62]$ and
IL-6 [18, 54,62]. However, some investigations have reported a decrease in anti-inflammatory markers like the mediator IL-10 $[18,40]$, while others showed an increase in the same mediator [54, 55, 62].

Nevertheless, due to the diversity of animal models, concentrations of juçara and variety of biomarkers it is difficult to infer more specific conclusions regarding the evaluated parameters.

Although berries are related to the improvement of the inflammatory state in humans [57], controlled clinical trials that evaluate the effect of juçara fruit, juice, or pulp on inflammatory parameters in humans are still lacking.

To better understand the relation between juçara fruit and modulation of inflammatory state, it is imminent that studies evaluating inflammation include not only isolated parameters, but a range of inflammatory biomarkers. For this reason, clinical trials should be encouraged.

The beneficial of the studies that evaluated the juçara effect on the inflammation biomarkers related their effects with the phenolic compounds content, particularly ACNs. However, it is important to highlight that the modulation of the intestinal microbiota is considered a mechanism by which ACNs can exert their benefits [63]. It is suggested that the downregulation of pro-inflammatory markers can occur through the modulation of the microbiota by the ACNs and their metabolites [54]. In this way, more studies in this area are needed.

\section{Other Effects}

Morais et al. [62] has shown that the addition $0.5 \%$ of juçara in maternal diet (TJ group) restored the fecal content of Bifidobacterium spp. and increased colonic zonules occludentes (ZO-1) mRNA expression. The ZO- 1 are membrane proteins that regulate cellular permeability and play role in tight junctions acting as a cellular barrier [64]. Thus, alterations in the expression of the ZO-1 mRNA expression protein may change the tight junction barrier improving intestinal permeability [65]. The authors hypothesize that the increase in Bifidobacterium spp. in juçara groups play role with the decrease of pro-inflammatory markers (shown in the Anti-Inflammatory section). This effect may also be related with decreased permeability of the intestinal mucosa due to increased ZO-1 expression. The authors associate the modulation of the intestinal microbiota with the metabolites of the juçara compounds by gastrointestinal tract.

The investigation performed by Morais et al. [54] also showed an increase in probiotic organisms (Lactobacillus spp.) in the colon of offspring whose mothers were fed with $0.5 \%$ of juçara. This fact acts with the downregulation of pro-inflammatory cytokines and the increase of anti-inflammatory mediators. The authors believe that the modulation of intestinal microbiota by the compounds present in the fruit juçara (fibers and polyphenols) promote the improvement of the inflammatory state, reducing the risk of developing chronic diseases.

Still on this path, the intestinal microbiota in anaerobic culture in vitro was modulated by juçara pulp. There was a significant increase in the population of bifidobacteria (beneficial bacteria) after $24 \mathrm{~h}$ of fermentation compared to the placebo group (negative control: basal nutrient without substrate and with prebiotic effect added). Most ACNs were degraded during digestion, but 
$46 \%$ of the total phenolic compounds resisted digestion, making them important sources of antioxidant activity that can reach the colon. This is the first study to assess the possible effects of prebiotic from juçara pulp. The researchers note that studies in humans should be encouraged to further prove the effectiveness of this pulp [26].

It is important to note that Felzenszwalb et al. [66] evaluated the toxicological effect of juçara pulp and observed that not adverse effects were reported on human healthy may be the ingredient a lot of food. Recently, juçara has also called attention in the development of new products. Geraldi et al. [67] added juçara pulp and commercial probiotic (Lactobacillus acidophilus) in yogurts to evaluate the survival probiotic in storage and after gastric and enteric digestion in vitro. Juçara pulp seems to be a good strategy in the production of yogurts increasing the resistance of probiotics until $14 \mathrm{~d}$ of storage even after the stimulation of gastrointestinal conditions. It is suggested with this study that polyphenols, in particular ACNs, may have improved the probiotic viability.

The study by Argentato et al. [55] also evaluated the supplementation of juçara $(0.5 \%)$ in maternal diets enriched with hydrogenated vegetable oil (with high content of trans fatty acids) on energy expenditure biomarker. The juçara intervention $(0.5 \%)$ increased the UCP-1 expression in brown adipose tissue, a parameter related with energy expenditure through thermogenesis. The authors attribute the results to bioactive compounds of juçara and believe that this fruit can be used to prevent obesity. However, the mechanisms by which phenolic compounds can affect thermogenesis are not yet totally understood. In addition, the composition of juçara fruits, rich in oleic and palmitic fatty acids, added still in a lipid-rich diet, could have also influenced the increase of UCP-1 expression.

There seems to be an emerging interest in relating juçara fruit to its effect on probiotics. Juçara fruit caused an increase of mRNA expression on ZO-1 and in probiotic populations (Bifidobacterium and Lactobacillus spp.). When added to dairy products, juçara fruit also provided probiotics with resistance even after being exposed to gastrointestinal conditions. In general, the authors relate the positive findings to the nutritional composition of juçara fruits rich in ACNs and unsaturated fatty acids. These results appear promising and could represent something in preventing chronic diseases. However, it is worth mentioning that the modulation of the intestinal microbiota by juçara fruit in humans has not yet been demonstrated.

\section{Conclusions}

Disease prevention has gained relevance in modern society. Food sources of natural and bioactive compounds can influence and help healthy bodies. It is necessary to support research to discover further new findings that confirm the biological effects of foods and beverages. It is important to consider that some foods can exert influence over the prevention of many chronic diseases by maintaining a healthy body.

The purpose of this review was critically to evaluate the existence of clinical data about juçara fruit and the biological effects. Data reviewed considered juçara, juice and freeze-dried juçara pulp in vivo and in vitro trials. A chapter about the nutritional characterization of juçara fruits was also included in order to help the understanding of its biological effects.

It is suggested that juçara supplementation may have positive effects on lipid peroxidation, modulation of the inflammatory state, improvement of blood glucose levels, and a possible beneficial effect on probiotic microorganisms. The fruit's effect on lipid profile parameters and antioxidant enzymes still seem to be a bit controversial when some studies show positive effects and others do not.

Most in vivo studies that analyze the biological effects of juçara fruit are performed on animal models. Although results seem promising, it is necessary to standardize important strategies such as concentration levels of prepared fruits, whether juice, pulp, or freeze-dried powder is used, and the time of consumption.

The positive results found after juçara administration are attributed to its interesting nutritional composition. Components of the juçara fruit such as phenolic compounds, especially ACNs and unsaturated fatty acids, are suggested as being responsible for these effects.

It is important to emphasize that phenolic compounds are metabolized by gut microbiota, and their metabolites can exert effects on gut permeability and contribute to the biological effects of the parent compounds. The bioavailability and metabolism of polyphenols may be different between animals and humans. In this way, there is a lack of clinical trial in humans to better clarify the effects of juçara pulp, or juice intake on human biology, affecting the prevention or treatment of chronic diseases.

As already mentioned, it is possible that sometimes juçara is named açaí to make it commercially relevant, despite belonging to a different species of palm [7]. With this present review, it is hoped that the potentially health benefit of juçara fruit and its derivatives have grown in importance concerning the human nutrition and strengthening its identity.

In addition, the palm tree $E$. edulis is an important palm for fauna and flora to the Atlantic Forest. Therefore, further knowledge about its main biological effects may promote the conservation of the species of palm, which is at risk of extinction nowadays.

\section{Supporting Information}

A flow chart of the selection of studies is available as Supporting Information (Fig. 1S).

\section{Acknowledgements}

We would like to thank the Conselho Nacional de Desenvolvimento Científico e Tecnológico (Edital Universal do CNPq, MCT/CNPq 14/2012, number 483929/2012-3) and the Coordenação de Aperfeiçoamento de Pessoal de Nivel Superior (CAPES). Finally, we would also like to express our thanks to the Graduate Program in Nutrition of the Federal University of Santa Catarina.

\section{Conflict of Interest}

The authors declare no conflicts of interest. 


\section{References}

[1] Crowe FL, Roddam AW, Key TJ, Appleby PN, Overvad K, Jakobsen MU, Tjønneland A, Hansen L, Boeing H, Weikert C, Linseisen J, Kaaks R, Trichopoulou A, Misirli G, Lagiou P, Sacerdote C, Pala V, Palli D, Tumino R, Panico S, Bueno-de-Mesquita HB, Boer J, Van Gils CH, Beulens JW, Barrocarte A, Rodríguez L, Larrañaga N, Sánchez MJ, Tormo MJ, Buckland G, Lund E, Hedblad B, Malander O, Jasson JH, Wennberg P, Wareham NJ, Slimani N, Romieu I, Jenab M, Danesh J, Gallo V, Norat T, Riboli E. Fruit and vegetable intake and mortality from ischaemic heart disease: results from the European Prospective Investigation into Cancer and Nutrition (EPIC)-Heart study. Eur Heart J 2011; 32: 1235-1243

[2] Spencer JPE, Crozier A, eds. Flavonoids and related Compounds: Bioavailability and Function of Flavonoids: oxidative Stress and Disease. 1st ed. Boca Raton, FL: CRC Press; 2012: 45-78

[3] Del Rio D, Rodriguez-Mateos A, Spencer JP, Tognolini M, Borges G, Crozier A. Dietary (poly)phenolics in human health: structures, bioavailability, and evidence of protective effects against chronic diseases. Antioxid Redox Signal 2013; 18: 1818-1892

[4] Costa AGV, Garcia-Diaz DF, Jimenez P, Silva PI. Bioactive compounds and health benefits of exotic tropical red-blackberries. J Funct Foods 2013; 5 : 539-549

[5] Harasym J, Oledzki R. Effect of fruit and vegetable antioxidants on total antioxidant capacity of blood plasma. Nutrition 2014; 30: 511-517

[6] Yamaguchi KKL, Pereira LFR, Lamarão CV, Lima ES, da Veiga-Junior VF. Amazon açai: chemistry and biological activities: a review. Food Chem 2015; 179: 137-151

[7] Chaimsohn FP, Chiquetto NC. Construção do marco legal para a produção de açaí de juçara: contribuições da "oficina interestadual sobre legislação, comercialização e marketing para exploração de frutos da palmeira juçara”. Rev Conexão 2013; 9: 244-253

[8] Borges GSC, Vieira FGK, Copetti C, Gonzaga LV, Zambiazi RC, Mancini Filho J, Fett R. Chemical characterization, bioactive compounds, and antioxidant capacity of jussara (Euterpe edulis) fruit from the Atlantic Forest in southern Brazil. Food Res Int 2011; 44: 2128-2133

[9] Borges GSC, Gonzaga LV, Jardini FA, Mancini Filho J, Heller M, Micke G, Costa ACO, Fett R. Protective effect of Euterpe edulis M. on Vero cell culture and antioxidant evaluation based on phenolic composition using HPLC-ESI-MS/MS. Food Res Int 2013; 51: 363-369

[10] Bicudo MO, Ribani RH, Beta T. Anthocyanins, phenolic acids and antioxidant properties of juçara fruits (Euterpe edulis M.) along the on-tree ripening process. Plant Food Hum Nutr 2014; 69: 142-147

[11] Inada KOP, Oliveira AA, Revorêdo TB, Martins ABN, Lacerda ECQ, Freire AS, Braz BF, Santelli RE, Torres AG, Perrone D, Monteiro MC. Screening of the chemical composition and occurring antioxidants in jabuticaba (Myrciaria jaboticaba) and jussara (Euterpe edulis) fruits and their fractions. J Funct Foods 2015; 17: 422-433

[12] Schulz M, Borges GSC, Gonzaga LV, Costa ACO, Fett R. Juçara fruit (Euterpe edulis Mart.): sustainable exploitation of a source of bioactive compounds. Food Res Int 2016; 89: 14-26

[13] da Silva NA, Rodrigues E, Mercadante AZ, De Rosso VV. Phenolic compounds and carotenoids from four fruits native from the Brazilian Atlantic forest. J Agric Food Chem 2014; 62: 5072-5084

[14] de Castro CA, Natali AJ, Cardoso LM, Ferreira-Machado AB, Novello AA, da Silva KA, Tafuri NF, da Mata SL, Pedrosa ML, Peluzio MC. Aerobic exercise and not a diet supplemented with jussara açaí (Euterpe edulis Martius) alters hepatic oxidative and inflammatory biomarkers in ApoE-deficient mice. Br J Nutr 2014; 112: 285-294

[15] Cardoso AL, Di Pietro PF, Vieira FGK, Boaventura BCB, De Liz S, Borges GSC, Fett R, Andrade DF, da Silva EL. Acute consumption of juçara juice (Euterpe edulis) and antioxidant activity in healthy individuals. J Funct Foods 2015a; 17: 152-162
[16] Cardoso LM, Novaes RD, Castro CA, Novello AA, Goncalves RV, Ricci-Silva ME, Ramos HJO, Peluzio MCG, Leite JPV. Chemical composition, characterization of anthocyanins and antioxidant potential of Euterpe edulis fruits: applicability on genetic dyslipidemia and hepatic steatosis in mice. Nutr Hosp 2015b; 32: 702-709

[17] Novello AA, Conceição LL, Dias MMS, Cardoso LM, de Castro CA, RicciSilva ME, Leite JPV, Peluzio MCG. Chemical characterization, antioxidant and antiatherogenic activity of anthocyanin-rich extract from Euterpe edulis Mart. in mice. J Food Nutr Res 2015; 54: 101-112

[18] Oyama LM, Silva FP, Carnier ], de Miranda DA, Santamarina AB, Ribeiro EB, Oller do Nascimento CM, De Rosso VV. Juçara pulp supplementation improves glucose tolerance in mice. Diabetol Metab Syndr 2016; 8: 1-8

[19] Schulz M, Borges GSC, Gonzaga LV, Seraglio SKT, Olivo IS, Azevedo MS, Nehring P, Gois JS, Almeida TS, Vitali L, Spudeit DA, Micke GA, Borges DLG, Fett R. Chemical composition, bioactive compounds and antioxidant capacity of juçara fruit (Euterpe edulis Martius) during ripening. Food Res Int 2015; 77: 125-131

[20] da Silva PPM, do Carmo LF, Silva GM, Silveira-Diniz MF, Casemiro RC, Spoto MHF. Physical, chemical, and lipid composition of juçara (Euterpe edulis Mart.) pulp. Braz J Food Nutr 2013; 24: 7-13

[21] Institute of Medicine (US). Panel on Micronutrients. Dietary reference intakes for vitamin $\mathrm{A}$, vitamin $\mathrm{K}$, arsenic, boron, chromium, copper, iodine, iron, manganese, molybdenum, nickel, silicon, vanadium, and zinc. Washington DC: National Academy Press; 2001. Available at https:// www.ncbi.nlm.nih.gov/books/NBK222310/. Accessed September 22, 2017

[22] Schulz M, Biluca FC, Gonzaga LV, Borges GD, Vitali L, Micke GA, de Gois JS, de Almeida TS, Borges DL, Miller PR, Costa AC, Fett R. Bioaccessibility of bioactive compounds and antioxidant potential of Juçara fruits (Euterpe edulis Martius) subjected to in vitro gastrointestinal digestion. Food Chem 2017; 228: 447-454

[23] Rufino MSM, Alves RE, Brito ES, Pérez--liménez ], Saura-Calixto F, Mancini Filho J. Bioactive compounds and antioxidant capacities of 18 non-traditional tropical fruits from Brazil. Food Chem 2010; 121: 996-1002

[24] Britton G, Khachik F. Carotenoids Nutrition and Health. In: Britton G, Liaaen-Jensen S, Pfander H, eds. Carotenoids in Food. Boston, MA: Birkhauser Basel; 2009: 45-66

[25] Schauss AG, Wu X, Prior RL, Ou B, Patel D, Huang D, Kababick JP. Phytochemical and nutrient composition of the freezedried Amazonian palm berry, Euterpe oleraceae Mart. (acai). J Agric Food Chem 2006; 54: 8598-8603

[26] Guergoletto KB, Costabile A, Flores G, Garcia S, Gibson GR. In vitro fermentation of Juçara pulp (Euterpe edulis) by human colonic microbiota. Food Chem 2016; 196: 251-258

[27] De Brito ES, Araújo MCP, Alves RE, Carkeet C, Clevidence B, Novotny JA. Anthocyanins present in selected tropical fruits: acerola, jambolão, jussara, and guajiru. J Agric Food Chem 2007; 55: 9389-9394

[28] Peron DV, Fraga S, Antelo F. Thermal degradation kinetics of anthocyanins extracted from juçara (Euterpe edulis Martius) and "Italia" grapes (Vitis vinifera L.), and the effect of heating on the antioxidant capacity. Food Chem 2017; 232: 836-840

[29] Vieira GS, Marques ASF, Machado MTC, Silva VM, Hubinger MD. Determination of anthocyanins and non-anthocyanin polyphenols by ultra performance liquid chromatography/electrospray ionization mass spectrometry (UPLC/ESI-MS) in jussara (Euterpe edulis) extracts. J Food Sci Technol 2017; 54: 2135-2144

[30] Vieira GS, Cavalcanti RN, Meireles MAA, Hubinger MD. Chemical and economic evaluation of natural antioxidant extracts obtained by ultrasound-assisted and agitated bed extraction from jussara pulp (Euterpe edulis). J Food Eng 2013; 119: 196-204

[31] Kang J, Thakali KM, Xie C, Kondo M, Tong Y, Ou B, Jensen G, Medina MB, Schauss AG, Wu X. Bioactivities of açaí (Euterpe precatoria Mart.) fruit pulp, superior antioxidant and anti-inflammatory properties to Euterpe oleracea Mart. Food Chem 2012; 133: 671-677 
[32] Lowe F. Biomarkers of oxidative Stress. In: Laher I, ed. Systems Biology of free Radicals and Antioxidants. Berlin, Germany: Springer; 2014: 65-87

[33] Halliwell B. Free radicals and antioxidants - quo vadis? Trends Pharmacol Sci 2011; 32: 125-130

[34] Freitas RB, Novaes RD, Gonçalves RV, Mendonça BG, Santos EC, Ribeiro AQ, Lima LM, Fietto LG, Peluzio MCG, Leite JPV. Euterpe edulis: extract but not oil enhances antioxidant defenses and protects against nonalcoholic fatty liver disease induced by a high-fat diet in rats. Oxid Med Cell Longev 2016; 2016: 8173876

[35] Del Bó C, Martini D, Porrini M, Klimis-Zacas D, Riso P. Berries and oxidative stress markers: an overview of human intervention studies. Food Funct 2015; 6: 2890-2917

[36] Motohashi N, Sakagami H. Anthocyanins as functional Food Colors. In: Hoop H, Swart P, eds. Bioactive Heterocycles VII. Berlin, Germany: Springer; 2009

[37] Kostogrys RB, Franczyk-Żarów M, Maślak E, Gajda M, Mateuszuk L, Jackson CL, Chłopicki S. Low carbohydrate, high protein diet promotes atherosclerosis in apolipoprotein E/low-density lipoprotein receptor double knockout mice (apoE/LDLR-/-). Atherosclerosis 2012; 223: 327-331

[38] Gonçalves RV, Novaes RD, Leite JP, Vilela EF, Cupertino MC, Nunes LG, Matta SL. Hepatoprotective effect of Bathysa cuspidata in a murine model of severe toxic liver injury. Int J Exp Pathol 2012; 93: 370-376

[39] Novaes RD, Gonçalves RV, Marques DC, Cupertino MC, Peluzio MC, Leite IP, Maldonado IR. Effect of bark extract of Bathysa cuspidata on hepatic oxidative damage and blood glucose kinetics in rats exposed to paraquat. Toxicol Pathol 2012; 40: 62-70

[40] Freitas RB, Rômulo DN, Bianca GM, Eliziária CS, Murilo SA, Luciano GF, Luciana ML, Maria do Carmo P, Reggiani VVG, João Paulo L. Euterpe edulis extracts positively modulates the redox status and expression of inflammatory mediators. Food Agric Immunol 2017. doi:10.1080/09540105. 2017.1360255

[41] Freitas RB, Melato FA, Oliveira JM, Bastos DS, Cardoso RM, Leite JPV, Lima LM. Euterpe edulis effects on cardiac and renal tissues of Wistar rats fed with cafeteria diet. Nutr Hosp 2017; 34: 186-192

[42] Bhooshan KP, Pandey KB, Rizv SI. Plant polyphenols as dietary antioxidants in human health and disease. Oxid Med Cell Longev 2009; 2: 270-278

[43] Lei XG, Zhu JH, Cheng WH, Bao Y, Ho YS, Reddi AR, Holmgren A, Arnér ES. Paradoxical roles of antioxidant enzymes: basic mechanisms and health implications. Physiol Rev 2016; 96: 307-364

[44] Tsuda T. Dietary anthocyanin-rich plants: biochemical basis and recent progress in health benefits studies. Mol Nutr Food Res 2012; 56: 159170

[45] Shih PH, Yeh CT, Yen GC. Effects of anthocyanidin on the inhibition of proliferation and induction of apoptosis in human gastric adenocarcinoma cells. Food Chem Toxicol 2005; 43: 1557-1566

[46] Toufektsian MC, Lorgeril M, Nagy N, Salen P, Donati MB, Giordano L, Mock HP, Peterek S, Matros A, Petroni K, Pilu R, Rotilio D, Tonelli C, de Leiris J, Boucher F, Martin C. Chronic dietary intake of plant-derived anthocyanins protects the rat heart against ischemia-reperfusion injury. J Nutr 2008; 138: 747-752

[47] Reis JF, Monteiro VVS, Gomes RS, do Carmo MM, da Costa GV, Ribera PC, Monteiro MC. Action mechanism and cardiovascular effect of anthocyanins: a systematic review of animal and human studies. J Transl Med 2016; 14: 315

[48] Rodriguez-Mateos A, Heiss C, Borges G, Crozier A. Berry (poly)phenols and cardiovascular health. J Agric Food Chem 2014; 62: 3842-3851

[49] Gordon T, Castelli WP, Hjortland MC, Kannel WB, Dawber TR. High density lipoprotein as a protective factor against coronary heart disease. The Framingham Study. Am J Med 1977; 62: 707-714
[50] Grammer TB, Kleber ME, Marz W, Silbernagel G, Siekmeier R, Wieland H, Pilz S, Tomaschitz A, Koenig W, Scharnagl H. Low-density lipoprotein particle diameter and mortality: the Ludwigshafen risk and cardiovascular health study. Eur Heart J 2015; 36: 31-38

[51] Nile SH, Park SW. Edible berries: bioactive components and their effect on human health. Nutrition 2014; 30: 134-144

[52] Kruger M], Davies N, Myburgh KH, Lecour S. Proanthocyanidins, anthocyanins and cardiovascular diseases. Food Res Int 2014; 59: 41-52

[53] Harris WS, Bulchandani D. Why do omega-3 fatty acids lower serum triglycerides? Curr Opin Lipidol 2006; 17: 387-393

[54] Morais CA, Oyama LM, Oliveira JL, Garcia MC, Rosso VV, Amigo LSM, Nascimento CM, Pisani LP. Jussara (Euterpe edulis Mart.) supplementation during pregnancy and lactation modulates the gene and protein expression of inflammation biomarkers induced by trans-fatty acids in the colon of offspring. Mediators Inflamm 2014; 2014: 987927

[55] Argentato PP, Morais CA, Santamarina AB, Cesar HC, Estadella D, Rosso VV, Pisani LP. Jussara (Euterpe edulis Mart.) supplementation during pregnancy and lactation modulates UCP-1 and inflammation biomarkers induced by trans-fatty acids in the brown adipose tissue of offspring. Clin Nutr Exp 2017; 12: 50-65

[56] Takikawa M, Inoue S, Horio F, Tsuda T. Dietary anthocyanin-rich bilberry extract ameliorates hyperglycemia and insulin sensitivity via activation of AMP-activated protein kinase in diabetic mice. I Nutr 2010; 140: 527-533

[57] Joseph SV, Edirisinghe I, Burton-Freeman BM. Berries: anti-inflammatory effects in humans. J Agric Food Chem 2014; 62: 3886-3903

[58] Tangney CC, Rasmussen HE. Polyphenols, inflammation, and cardiovascular disease. Curr Atheroscler 2013; 15: 324

[59] Wallace TC. Anthocyanins in cardiovascular disease. Adv Nutr 2011; 2 $1-7$

[60] Zhang H, Liu R, Tsao R. Anthocyanin-rich phenolic extracts of purple root vegetables inhibit pro-inflammatory cytokines induced by $\mathrm{H} 2 \mathrm{O} 2$ and enhance antioxidant enzyme activities in Caco-2 cells. J Funct Foods 2016; 22: 363-375

[61] Jiang M, Klein M, Zanger UM, Mohammad MK, Cave MC, Gaikwad NW, Dias NJ, Selcer KW, Guo Y, He J, Zhang X, Shen Q, Qin W, Li J, Li S, Xie W. Inflammatory regulation of steroid sulfatase: A novel mechanism to control estrogen homeostasis and inflammation in chronic liver disease. J Hepatol 2016; 64: 44-52

[62] Morais CA, Oyama LM, Conrado RM, Rosso VV, Nascimento CO, Pisani LP. Polyphenols-rich fruit in maternal diet modulates inflammatory markers and the gut microbiota and improves colonic expression of ZO-1 in offspring. Food Res Int 2015; 77: 186-193

[63] Jakobsdottir G, Blanco N, Xu J, Ahrné S, Molin G, Sterner O, Nyman M. Formation of short-chain fatty acids, excretion of anthocyanins, and microbial diversity in rats fed blackcurrants, blackberries, and raspberries. J Nutr Metab 2013; 1-12

[64] Hamada K, Shitara Y, Sekine S, Horie T. Zonula occludens-1 alterations and enhanced intestinal permeability in methotrexate-treated rats. Cancer Chemother Pharmacol 2010; 66: 1031-1038

[65] Hamada K, Kakigawa N, Sekine S, Shitara Y, Horie T. Disruption of ZO-1/ claudin-4 interaction in relation to inflammatory responses in methotrexateinduced intestinal mucositis. Cancer Chemother Pharmacol 2013; 72: 757-765

[66] Felzenszwalb I, da Costa Marques MR, Mazzei JL, Aiub CAF. Toxicologica evaluation of Euterpe edulis: a potential superfruit to be considered. Food Chem Toxicol 2013; 58: 536-544

[67] Geraldi MV, Tulini FL, Souza VM, De Martinis ECP. Development of yoghurt with juçara pulp (Euterpe edulis M.) and the probiotic Lactobacillus acidophilus La5. Probiotics Antimicrob Proteins 2017. doi:10.1007| s12602-017-9280-z 